УДК 552.12:549.621.9(571.65)

\title{
ОПЫТ ПЕТРОЛОГИЧЕСКОЙ ИНТЕРПРЕТАЦИИ РЕАКЦИОННЫХ СТРУКТУР В ГРАНАТОВЫХ МЕТАУЛЬТРАМАФИТАХ ОМОЛОНСКОГО МАССИВА
}

\author{
О. В. Авченко ${ }^{1}$ И. Л. Жуланова ${ }^{2}$, А. А. Карабцов \\ IФГБУН Дальневосточный геологический институт ДВО РАН, г. Владивосток \\ E-mail: sirenevka@mail.ru \\ ${ }^{2}$ ФББУН Северо-Восточный комплексный научно-исследовательский институт \\ им. Н. А. Шило ДВО РАН, г. Магадан \\ E-mail: metamor@neisri.ru
}

\begin{abstract}
Изучены реакционные структуры в гранатовых метаультрамафитах из Ауланджинского блока фундамента Омолонского массива, запечатленные в окружающих гранат келифитовых каймах, сложенных ортопироксеном, плагиоклазом, роговой обманкой, изредка - клинопироксеном. Расчеты P-T параметров по сосуществующим составам гранатов и пироксенов на основе программы TWQ свидетельствуют о нарушении принципа локального равновесия в реакционных структурах по потенциалу глинозема. Пониженное содержание глинозема в пироксенах из реакционных структур (или недопоглощение глинозема пироксенами в процессе реакции) служит причиной нереально высоких оценок давления. В то же время, если расчет Р-Т оценок проводить по составу включений клинопироксена, расположенных внутри кристаллов граната, и сосуществующему составу граната, то получаются Р-Т параметры метаморфизма, хорошо согласующиеся с ранее полученными результатами. Новые данные позволяют заключить, что давление при формировании наиболее глубинных пород, наблюдаемых на современном срезе Ауланджинского блока, составляло примерно 7000 бар при температуре $950-1000^{\circ} \mathrm{C}$.
\end{abstract}

Ключевые слова: Омолонский массив, метаморфизм, программа TWQ, реакционные структуры, потенциал глинозема.

DOI: 10.34078/1814-0998-2019-4-29-37

\section{ВВЕДЕНИЕ}

Омолонский массив - один из интереснейших структурных элементов зоны перехода континент - океан на Северо-Востоке Азии, в котором четко обособлены древний кристаллический фундамент и слабо деформированный рифейскомезозойский вулканогенно-осадочный чехол. Выходы фундамента сосредоточены в основном на юге массива. Наиболее интересен Ауланджин-

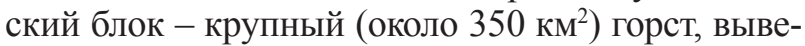
денный на современный срез по системе разломов, ограничивающих массив с юго-востока (рис. 1). На северо-западе метаморфиты несогласно перекрыты рифейскими кварцитовидными песчаниками. В границах Ауланджинского блока реконструируется фрагмент (западная половина) купола, ядро которого слагают чарнокитоиды. Среди них в качестве реликтов субстрата повсеместно 2019

(C) Авченко О. В., Жуланова И. Л., Карабцов А. А., наблюдаются амфибол-двупироксеновые, иногда с гранатом, кристаллосланцы, изредка - лейкократовые гранулиты. На крыле вскрыт стратифицированный разрез, где преобладают богатые кальцием мезократовые гнейсы и амфиболиты, чередующиеся с глиноземистыми толщами. Между ядром и крылом закартирована широкая (4-5 км) полоса биотитовых гранито-гнейсов, залечивающих зону скрытого несогласия (Жуланова, 1990). В одной из разновидностей биотитовых гнейсов Е. В. Бибиковой (1989) впервые в Советском Союзе были установлены акцессорные цирконы, U-Pb возраст которых превысил 3 млрд лет (получен при измерениях методом ID-TIMS по навескам). Другую специфическую принадлежность Ауланджинского блока составляют меланократовые метаморфические породы, сложенные гранатом, клинопироксеном и роговой обманкой. Они впервые были описаны в литературе как эклогитовые сланцы (Гельман, Терехов, 1973), нами отнесены к группе гранатовых 


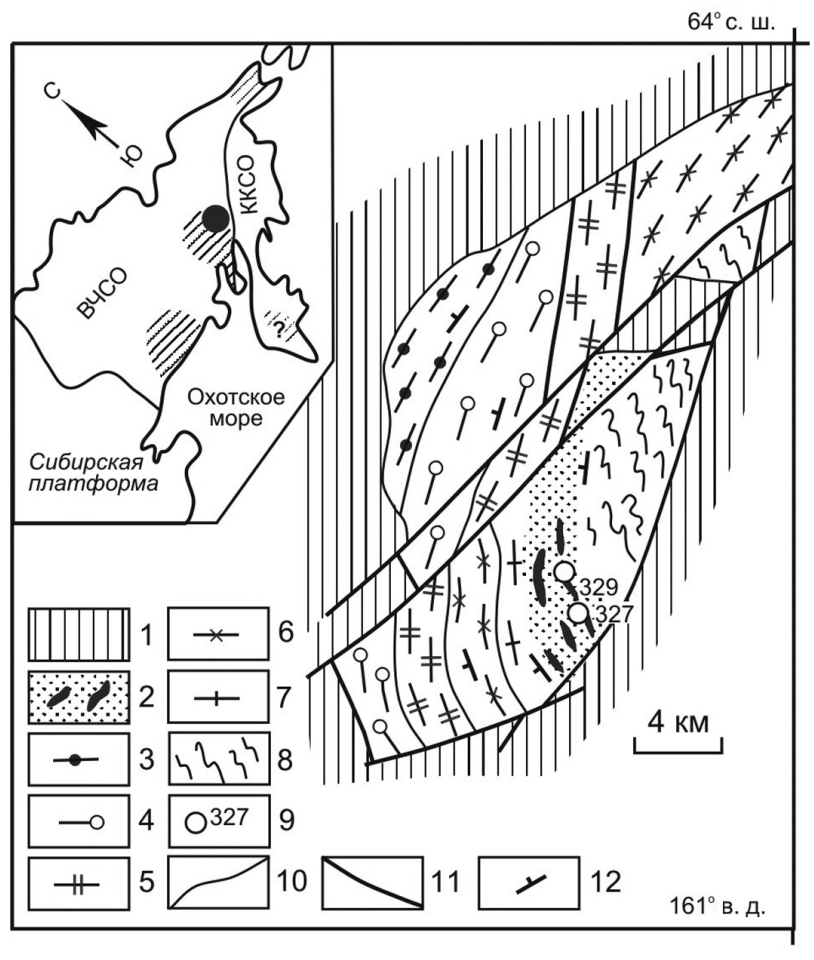

Puc. 1. Схематическая геологическая карта Ауланджинского блока фундамента Омолонского массива.СоставилаИ. Л. Жуланова (1990): 1 - рифейские и палеозойские осадочные отложения; 2-8 - нижний архей: 2 -биотитовые гранито-гнейсы с линзами гранатовых метаультрамафитов, 3 - гранат-биотитовые плагиогнейсы, биотит-гиперстеновые сланцы, 4 диопсидовые плагиогнейсы, двупироксен-амфиболовые сланцы, гранат-биотитовые гнейсы, 5 амфиболиты, диопсид-амфиболовые сланцы, 6 преимущественно гранат-биотитовые гнейсы, иногда кордиеритсодержащие, 7 - диопсидовые амфиболиты, двупироксен-амфиболовые, гранат-диопсид-амфиболовые сланцы, 8 - чарнокитоиды, амфибол-двупироксеновые сланцы, лейкократовые гранулиты; 9 - места отбора образцов, номера точек наблюдения; 10 - геологические границы; 11 - разломы; 12 - элементы залегания полосчатости метаморфических пород. На врезке: заштриховано - районы распространения выходов дорифейских метаморфических образований в ВЧСО (с юго-запада на северо-восток: Охотский, Омолоно-Тайгоносский, Восточно-Чукотский). ВЧСО - Верхояно-Чукотская мезозойская складчатая область. ККСО - Корякско-Камчатская кайнозойская складчатая область. Черный кружок местоположение Ауланджинского блока. Координаты точки отбора образцов 329а и 329-5: 6342'20" с. ш., 16047'40" в. д. Координаты точки отбора образца 327: $63^{\circ} 42^{\prime} 00^{\prime \prime}$ с. ш., $160^{\circ} 50^{\prime} 30^{\prime \prime}$ в. Д.

Fig. 1. Schematic geological map of the Aulandzha block of the Omolon massif basement, compiled by I. L. Zhulanova (1990): 1 - Riphean and Paleozoic sedimentary deposits; 2-8 - Lower Archean: 2 - biotite and granite gneisses with lenses of metaultramafite garnet, 3 - garnet-biotite plagiogneisses, biotite-hypersthene shales, 4 - diopside plagiogneisses, bypyroxene-amphibole shales, garnet-biotite gneisses, 5 - amphibolites, diopside-amphibole shales, 6 - mainly garnet-biotite gneisses, 7 - diopside amphibolites, bypyroxene-amphiboles, garnet-diopside-amphibole shales, 8 - charnockitoides, amphibole-bypyroxene shales, leucocratic granulites; 9 - sampling points, numbers of observation points; 10 - geological boundaries; 11 - faults; 12 - elements of metamorphic rocks banding occurrence. Inset: hatched - areas of distribution of pre-Riphean metamorphic rock exposures in VChSO (from the southwest to the northeast: Okhotsk, Omolon-Taygonos, East Chukotka). VCFA - Verkhoyansk-Chukotka Mesozoic folded area. KKFA - Koryak-Kamchatka Cenozoic folded area. The black circle marks the location of the Aulandzha block. Coordinates of sampling points 329a and 329-5: 63'42’20" N, 160 47'40" E. Coordinates of Sampling Point 327: $63^{\circ} 42^{\prime} 00^{\prime \prime} \mathrm{N}, 160^{\circ} 50^{\prime} 30^{\prime \prime} \mathrm{E}$

метаультрамафитов (Жуланова и др., 2014). Образуют линзовидные тела мощностью до $50 \mathrm{~m}$, цепочки которых, прослеженные внутри полосы гранито-гнейсов на расстояние около 5 км, пространственно тяготеют к ядру купола и конформно вписываются в его общую структуру (см. рис. 1). Интерпретируются как тектонические отторженцы подошвы чарнокитоидной антиформы. Недавно выполненное В. В. Акининым SHRIMP-RG датирование цирконов из гранатовых жедрититов - продуктов регрессивного изменения гранатовых метаультамафитов, подтвердило данные петрографии о полиметаморфизме гранатовых метаультрамафитов и позволило конкретизировать время проявления отдельных эпизодов метаморфизма (Акинин, Жуланова, 2016). Самый ранний (из установленных) эпизод становления полиметаморфического комплекса относится к палеоархею (3.25-3.22 млрд лет, возможно, до 3.4 млрд лет). Он записан в ядрах крупных кристаллов циркона с осцилляторной зональностью и повышенными концентрациями тяжелых редких земель и титана. Слабее выражен неоархейский (около 2.6 млрд лет) этап метаморфизма. Наиболее ярко проявлено палеопротерозойское (1.9 млрд лет) метаморфическое событие, которое зафиксировано в рекристаллизованных каймах крупных кристаллов и в мелких новообразованных зернах циркона.

Петротип гранатовых метаультрамафитов составляют среднезернистые разновидности гранобластовой структуры, сложенные гранатом, клинопироксеном и коричневой роговой обманкой примерно в равных соотношениях; в качестве примеси (0-10\%) отмечаются ортопироксен, шпинель, рутил, ильменит и др. Характерной особенностью является повсеместное развитие келифитовых кайм, отделяющих гранат от окружающих минералов. Их изучение представляет большой интерес, поскольку позволяет на количествен- 
ном уровне проследить направленность изменения условий метаморфизма. Ранее мы детально исследовали реакционные структуры в гранатовых жедрититах и сапфирин-шпинелевых метаультрамафитах на примере обр. 329а (в котором В. В. Акинин изучал циркон) и 329-5, отобранных из единственного в своем роде небольшого линзовидного тела гранатовых метаультрамафитов $(8 \times 20$ м), петрографические особенности которых (минеральное разнообразие, гетерозернистое, вплоть до крупно- и гигантозернистого, сложение, текстурная неоднородность, отсутствие кристаллизационной сланцеватости) свидетельствуют о мощно проявленных процессах перекристаллизации с возможным участием метасоматоза (Жуланова и др., 2014).

Реконструированные в работе (Авченко и др., 2018) Р-Т условия образования реакционных структур мы отнесли к этапу наложения метаморфизма амфиболитовой фации, тогда как параметры раннего (гранулитового) этапа, в особенности по величине давления, оставались не вполне проясненными. Ниже излагаются результаты изучения реакционных структур на примере обр. 327, отобранного из значительно слабее измененных гранатовых метаультрамафитов в целях более точного приближения к оценке Р-Т условий раннего этапа метаморфизма.

\section{ОПИСАНИЕ РЕАКЦИОННОЙ СТРУКТУРЫ И СОСТАВА МИНЕРАЛОВ}

Образец 327 отобран И. Л. Жулановой примерно в 1.5 км к юго-юго-востоку от точки наблюдения 329 (координаты мест отбора см. в подписи к рис. 1). Здесь, среди лейкократовых гнейсов, по коренным выходам и крупноглыбовому элювию прослежено на расстоянии не менее 100 м маломощное (до 3 м) тело среднезернистых метаультрамафитов с элементами полосчатости, обусловленной неравномерной концентрацией выделений граната (размер зерен - 25 мм, ширина полосок - 1-3 см), с которым тесно ассоциирует черная ярко блестящая роговая обманка. Местами субпараллельно полосчатости располагаются линзовидно-прерывистые кварц-плагиоклазовые лейкосомы, близ которых гранат и роговая обманка всегда перекристаллизованы с укрупнением. Вокруг большинства кристаллов граната невооруженным глазом различимы матово-серые или серовато-белые реакционные оторочки (1-5 мм).

На микроанализаторе исследован участок

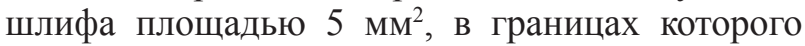
оторочка сложена симплектитом ортопироксена, плагиоклаза и роговой обманки со средней величиной индивидуальных зерен 0.01-1 мм (рис. 2). На удалении от порфиробластов граната те же минералы более крупные, и к ним иногда присоединяется клинопироксен.

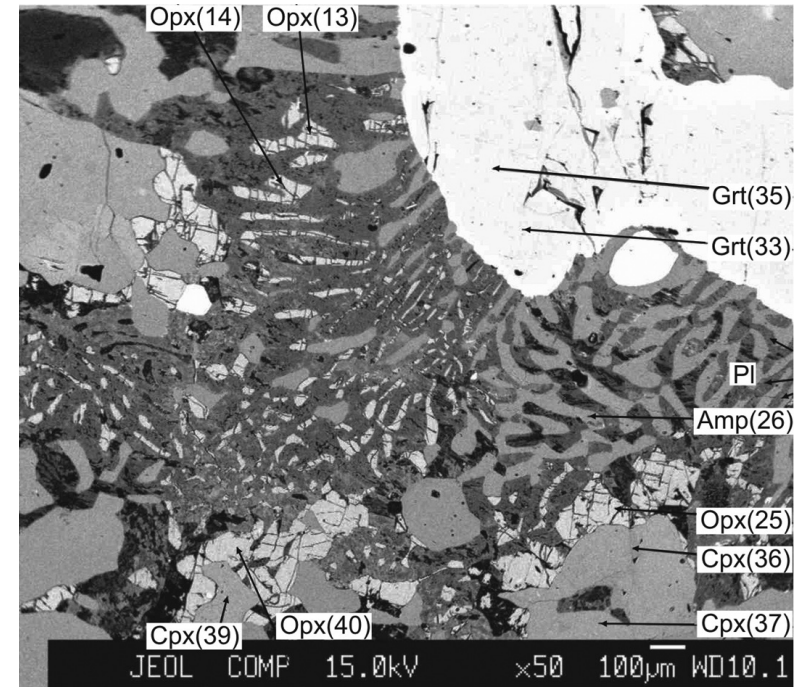

Puc. 2. Реакционная структура в обр. 327. Отчетливо виден распад граната (Grt) на ортопироксен (Opx), амфибол (Amp) и плагиоклаз (Pl). Цифры здесь и на рис. 3 - номера анализов в таблице. Микрофотография в отраженных электронах

Fig. 2. Reactionary structure in Sample 327. The decay of garnet (Grt) into orthopyroxene (Opx), amphibole (Amp), and plagioclase (Pl) is clearly visible. Figures here and in Fig. 3 are numbers of analyses in the Table. Microphotographed in back-scattered electrons

Кроме того, клинопироксен присутствует в кристаллах граната в виде индивидуальных включений с четкими и ровными контактами между ним и вмещающей матрицей (рис. 3). Таким образом, гранат в данном случае замещается минеральной ассоциацией ортопироксена, плагиоклаза и роговой обманки, тогда как первичная ассоциация состояла, видимо, из граната, клинопироксена, роговой обманки и, возможно, небольшого количества плагиоклаза.

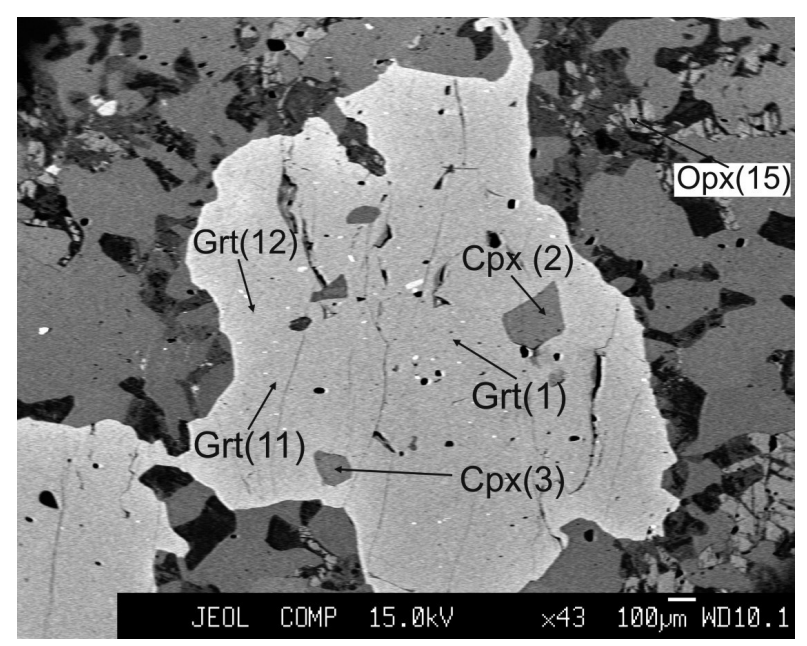

Puc. 3. Кристалл граната (Grt) с включениями клинопироксена (Сpх). Микрофотография в отраженных электронах

Fig. 3. Garnet crystal (Grt) with clinopyroxene inclusions (Cpx). Microphotographed in back-scattered electrons 


\begin{tabular}{|c|c|c|c|c|c|c|c|c|c|c|c|c|c|c|c|c|c|c|c|c|c|c|c|c|c|c|}
\hline & 究 $\infty$ & 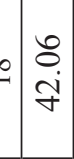 & $\stackrel{?}{-}$ & $\stackrel{⿱}{\stackrel{\Xi}{ \pm}}$ & $\begin{array}{l}n \\
\\
\end{array}$ & $\because$ & 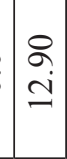 & $\begin{array}{l}0 \\
\\
=\end{array}$ & $\begin{array}{l}\infty \\
\infty \\
i\end{array}$ & $\stackrel{f}{\Im}$ & $\begin{array}{l}n \\
\tilde{n} \\
\infty \\
\alpha\end{array}$ & \begin{tabular}{l}
$\infty$ \\
- \\
\hdashline \\
$\dot{0}$
\end{tabular} & $\begin{array}{c}\infty \\
\infty \\
0 \\
0\end{array}$ & $\begin{array}{l}n \\
\tilde{n} \\
i\end{array} \mid$ & 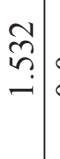 & $\begin{array}{l}0 \\
\dot{0}\end{array}$ & $\stackrel{0}{0}$ & $\begin{array}{l}8 \\
\triangleright \\
\infty \\
i \\
i\end{array}$ & $\begin{array}{l}\circ \\
\stackrel{2}{\Sigma} \\
-\end{array}$ & 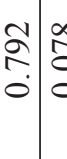 & $\begin{array}{l}\infty \\
\vdots \\
\vdots \\
0\end{array}$ & 1 & 1 & $\stackrel{n}{m}$ & 1 & 1 \\
\hline 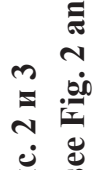 & 究二 & $=\begin{array}{l}\mathscr{8} \\
\dot{i}\end{array}$ & $\stackrel{\leftrightarrow}{-}$ & $\begin{array}{l}\tilde{a} \\
\dot{\Xi}\end{array}$ & $\stackrel{\infty}{\stackrel{\infty}{c}}$ & $\ddot{0}$ & $\underline{n}$ & $\stackrel{\sim}{n}$ & $\begin{array}{l}\partial \\
\grave{i}\end{array}$ & ?ִ & $\begin{array}{l}\hat{\sim} \\
\infty \\
\alpha\end{array}$ & $\begin{array}{c}0 \\
= \\
6 \\
0\end{array}$ & 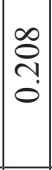 & 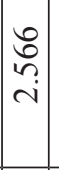 & ก̊. & $\begin{array}{l}\circ \\
\dot{0}\end{array}$ & $\because$ & 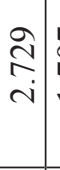 & $\stackrel{2}{=}$ & & 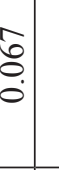 & 1 & 1 & గొ & 1 & 1 \\
\hline 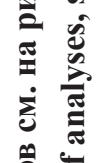 & 安 & 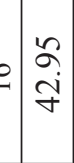 & $\stackrel{乛}{-}$ & $\begin{array}{l}\infty \\
m \\
\dot{I}\end{array}$ & 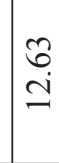 & $\stackrel{0}{0}$ & $\begin{array}{l}\stackrel{0}{n} \\
\stackrel{2}{2}\end{array}$ & 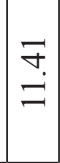 & 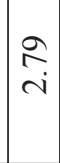 & 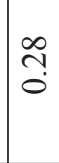 & $\begin{array}{l}n \\
m \\
2 \\
\alpha\end{array}$ & 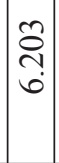 & \begin{tabular}{c}
0 \\
$\infty$ \\
\hdashline \\
0
\end{tabular} & $\mid \begin{array}{c}\infty \\
\stackrel{+}{+} \\
\sim \\
\sim\end{array}$ & 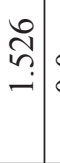 & $\stackrel{0}{\circ}$ & $\because$ & \begin{tabular}{c}
$\mathcal{Y}$ \\
\multirow{\infty}{*}{} \\
$i$
\end{tabular} & \begin{tabular}{l}
8 \\
$\stackrel{0}{\circ}$ \\
\hdashline
\end{tabular} & 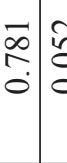 & $\begin{array}{l}1 \\
\tilde{2} \\
0 \\
0\end{array}$ & 1 & 1 & $\stackrel{n}{m}$ & 1 & 1 \\
\hline 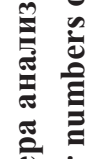 & 仓े & 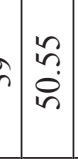 & ?n & 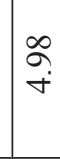 & $\begin{array}{l}n \\
n \\
\infty\end{array}$ & $\because$ & $\frac{0}{m}$ & $\mid \begin{array}{l}\mathfrak{g} \\
\dot{i}\end{array}$ & $\hat{n}$ & $\because$ & $\begin{array}{l}n \\
\mathfrak{8} \\
\dot{8}\end{array}$ & $\mid \begin{array}{l}\hat{0} \\
\infty \\
- \\
-\end{array}$ & $\overrightarrow{0}$ & 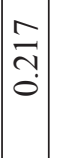 & 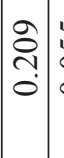 & $\begin{array}{l}n \\
0 \\
0 \\
0\end{array}$ & $\because$ & $\begin{array}{l}\stackrel{\imath}{a} \\
\stackrel{0}{0}\end{array}$ & \begin{tabular}{c|c}
$\stackrel{1}{2}$ & \\
$\infty$ \\
$\circ$
\end{tabular} & & $\stackrel{0}{\circ}$ & 1 & 1 & 1 & స్ & ?ִ \\
\hline 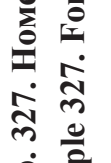 & 仓े & $=\left[\begin{array}{c}n \\
i \\
i n \\
i n\end{array}\right.$ & 文 & Fे & $\begin{array}{l}n \\
\tilde{a} \\
\infty\end{array}$ & $\because$ & 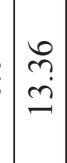 & 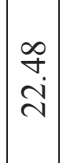 & $\vec{t}$. & $\because$ & 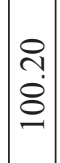 & $\begin{array}{l}\infty \\
\infty \\
\infty \\
- \\
-\end{array}$ & $\begin{array}{l}\overrightarrow{0} \\
\dot{0}\end{array}$ & 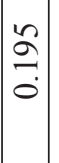 & $\begin{array}{l}\overrightarrow{\tilde{\sigma}} \\
\tilde{0}\end{array}$ & $\begin{array}{l}n \\
0 \\
0\end{array}$ & $\because$ & $\begin{array}{c}\tilde{n} \\
\stackrel{0}{0}\end{array}$ & $\begin{array}{c}\bar{\sigma} \\
\dot{\alpha} \\
\dot{0}\end{array}$ & & $\stackrel{0}{0}$ & 1 & 1 & 1 & ֶֻ & $\overbrace{}^{n}$ \\
\hline 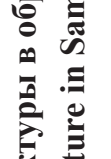 & 己े & 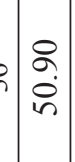 & $\stackrel{\text { I }}{0}$ & $\stackrel{\sim}{\sim} \underset{+}{+}$ & $\underset{\infty}{\mathbb{N}}$ & $\stackrel{0}{0}$ & $\begin{array}{l}\hat{n} \\
\ddot{2}\end{array}$ & 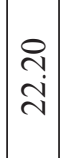 & $\stackrel{f}{\leftarrow}$ & $\because$ & $\frac{9}{8}$ & $\mid \begin{array}{c}\infty \\
\infty \\
\infty \\
-i\end{array}$ & $\mid \begin{array}{l}1 \\
0 \\
0 \\
0\end{array}$ & $\mid$\begin{tabular}{c}
0 \\
$\infty$ \\
\hdashline \\
0
\end{tabular} & 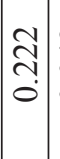 & $\begin{array}{l}\stackrel{a}{0} \\
\vdots \\
0\end{array}$ & $\because$ & $\begin{array}{c}m \\
\stackrel{2}{0}\end{array}$ & 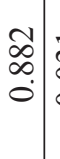 & & $\stackrel{0}{\circ}$ & 1 & 1 & 1 & กิ & $\underset{\sigma}{0}$ \\
\hline 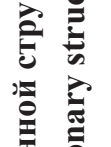 & 仓े $m$ & $\mid \begin{array}{c}\mathbb{N} \\
\dot{q} \\
\dot{q}\end{array}$ & §. & $\hat{\sigma}$ & $\underset{\infty}{\varnothing}$ & $\because$ & 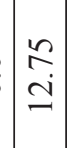 & $\frac{\grave{\partial}}{\grave{\lambda}}$ & $\begin{array}{l}8 \\
0 \\
0\end{array}$ & $\because$ & $\begin{array}{l}n \\
0 \\
\dot{8} \\
0\end{array}$ & 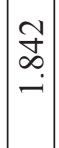 & $\mid \begin{array}{l}a \\
\vdots \\
0 \\
0\end{array}$ & $\left|\begin{array}{c}0 \\
\stackrel{0}{0} \\
0\end{array}\right|$ & 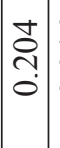 & $\begin{array}{l}0 \\
0 \\
0 \\
0\end{array}$ & $\because$ & $\begin{array}{l}\stackrel{t}{尺} \\
\stackrel{0}{0}\end{array}$ & 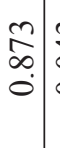 & $\begin{array}{c}\tilde{f} \\
\stackrel{0}{0} \\
\dot{0}\end{array}$ & $\stackrel{0}{\circ}$ & 1 & 1 & 1 & ֶָ. & $\begin{array}{l}\dot{n} \\
\infty \\
\infty\end{array}$ \\
\hline 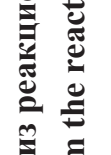 & 仓े & $\mid \begin{array}{l}0 \\
n \\
q \\
q\end{array}$ & $\frac{n}{0}$ & $\frac{7}{6}$ & $\underset{\infty}{\stackrel{\infty}{0}}$ & $\ddot{0}$ & 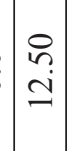 & $\frac{n}{\grave{\lambda}}$ & $\stackrel{2}{2}$ & $\ddot{0}$ & 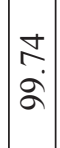 & 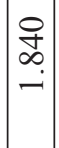 & $\overrightarrow{\widehat{ح}}$ & సิ & $\left|\begin{array}{c}\infty \\
\infty \\
\hdashline \\
0\end{array}\right|$ & $\begin{array}{l}\text { Tे } \\
0 \\
0\end{array}$ & $\because$ & $\begin{array}{l}\tilde{\sigma} \\
\tilde{\sigma} \\
\dot{0}\end{array}$ & \begin{tabular}{c|c}
$\tilde{n}$ & \\
$\infty$ \\
$\infty$ \\
$\dot{0}$
\end{tabular} & 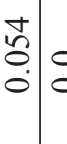 & $\stackrel{\circ}{\circ}$ & 1 & 1 & 1 & సֶ. & $\stackrel{\infty}{\infty}$ \\
\hline 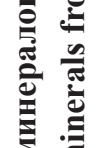 & Eे & $\hat{c} \begin{array}{c}\sigma \\
0 \\
\dot{q}\end{array}$ & $\because$ & $\begin{array}{l}\tilde{N} \\
\stackrel{N}{N}\end{array}$ & 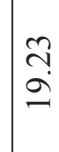 & $\because$ & $\begin{array}{l}8 \\
0 \\
\infty\end{array}$ & $\stackrel{\widehat{N}}{\beth}$ & $\ddot{0}$ & $\ddot{0}$ & $\begin{array}{l}0 \\
\tilde{i} \\
i \\
0 \\
\end{array}$ & $\begin{array}{c}\infty \\
0 \\
\dot{\sigma} \\
\dot{n}\end{array}$ & $\because$ & 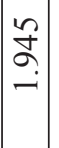 & I & $\begin{array}{l}\infty \\
0 \\
0 \\
0\end{array}$ & $\because$ & $\begin{array}{l}\tilde{n} \\
\tilde{a} \\
\hat{o}\end{array}$ & $\begin{array}{c}\tilde{2} \\
\hat{\alpha} \\
0 \\
0\end{array}$ & $\stackrel{\circ}{\circ}$ & $\stackrel{0}{\circ}$ & $n$ & సे & 1 & 1 & 1 \\
\hline 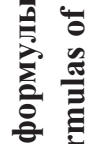 & E̋ & $=\frac{\tilde{m}}{\vec{\nabla}}$ & $\because$ & $\begin{array}{l}n \\
\tilde{n} \\
i\end{array}$ & $\begin{array}{l}\mathbb{U} \\
\infty \\
\infty \\
0\end{array}$ & $\because$ & $\begin{array}{l}\tilde{\alpha} \\
\infty\end{array}$ & $\mid \begin{array}{l}\infty \\
\vdots \\
0 \\
\end{array}$ & $\ddot{0}$ & $\because$ & $\begin{array}{l}\tilde{f} \\
\dot{\sigma} \\
\stackrel{0}{0}\end{array}$ & $\begin{array}{c}\hat{\sigma} \\
\tilde{\sigma} \\
\dot{\gamma}\end{array}$ & $\stackrel{0}{0}$ & 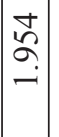 & \begin{tabular}{l}
0 \\
\multirow{2}{*}{} \\
$=$
\end{tabular} & $\stackrel{0}{\circ}$ & $\stackrel{0}{0}$ & $\begin{array}{l}\hat{\sigma} \\
\hat{\sigma} \\
0\end{array}$ & $\begin{array}{c}n \\
0 \\
\infty \\
0 \\
0\end{array}$ & & $\because$ & 茪 & సे & 1 & 1 & 1 \\
\hline 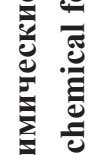 & $\pm \simeq$ & $\mid$\begin{tabular}{c}
0 \\
\hdashline \\
$\dot{\gamma}$
\end{tabular} & $\stackrel{0}{\circ}$ & 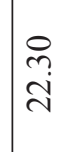 & $\stackrel{\vec{\sigma}}{\vec{\lambda}}$ & त̂. & $\begin{array}{l}0 \\
\vdots \\
a\end{array}$ & $\begin{array}{c}\hat{N} \\
\infty\end{array}$ & 0 & $\because$ & 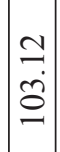 & $\begin{array}{c}\hat{\widehat{\sigma}} \\
\dot{r}\end{array}$ & $\stackrel{0}{0}$ & 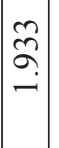 & $\mid \overrightarrow{\widetilde{N}}$ & 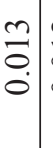 & 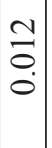 & 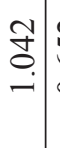 & 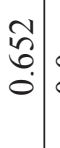 & & $\stackrel{0}{\circ}$ & $\begin{array}{l}0 \\
n \\
n\end{array}$ & $\vec{\jmath}$ & 1 & 1 & 1 \\
\hline 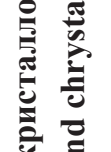 & E $=$ & $\mid \begin{array}{c}\tilde{\sigma} \\
\dot{z} \\
\gamma\end{array}$ & $\stackrel{0}{\circ}$ & $\stackrel{\circ}{\stackrel{\leftrightarrow}{\sim}}$ & $\begin{array}{l}\text { ثn } \\
\text { ¿n }\end{array}$ & กิ & $\begin{array}{l}3 \\
\sigma \\
\sigma\end{array}$ & $\begin{array}{c}\tilde{S} \\
\infty \\
\infty\end{array}$ & $\because$ & $\stackrel{0}{\circ}$ & 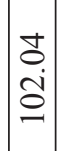 & $\begin{array}{l}\vec{\Xi} \\
\dot{n}\end{array}$ & $\because$ & $\frac{\partial}{\partial}$ & $\mid \begin{array}{c}\stackrel{+}{~} \\
\stackrel{-}{-}\end{array}$ & $\stackrel{.}{\circ}$ & $\begin{array}{l}1 \\
0 \\
0 \\
0\end{array}$ & 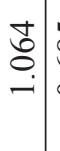 & $\begin{array}{l}n \\
\infty \\
0 \\
0 \\
0\end{array}$ & $\stackrel{\circ}{\circ}$ & $\stackrel{0}{\circ}$ & 菅 & तె & 1 & 1 & 1 \\
\hline 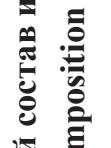 & 苛- & $\mid \begin{array}{l}\dot{I} \\
\stackrel{o}{q}\end{array}$ & $\because$ & $\begin{array}{l}\bar{n} \\
\text { ה }\end{array}$ & $\stackrel{\Xi}{\beth}$ & 0 & $\left.\mid \begin{array}{c}\infty \\
\infty \\
\infty\end{array}\right]$ & $\begin{array}{l}0 \\
0 \\
\infty \\
\infty\end{array}$ & $\because$ & 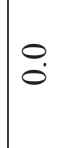 & $\begin{array}{l}0 \\
\infty \\
i \\
i \\
\end{array}$ & $\begin{array}{c}\dot{\partial} \\
\dot{\partial} \\
\dot{\gamma}\end{array}$ & $\stackrel{0}{\circ}$ & $\stackrel{n}{-}$ & $\left|\begin{array}{l}\infty \\
0 \\
\\
-\end{array}\right|$ & 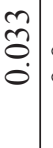 & $\because$ & \begin{tabular}{l|l}
\multicolumn{1}{c}{} \\
$\infty$ \\
0 \\
\hdashline \\
-
\end{tabular} & $\begin{array}{l}\infty \\
0 \\
0 \\
0\end{array}$ & & $\because$ & 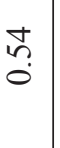 & స̃ & 1 & 1 & 1 \\
\hline 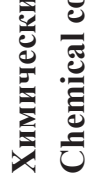 & 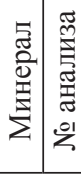 & $\stackrel{0}{N}^{N}$ & $\stackrel{O^{N}}{2}$ & $\frac{0^{m}}{e^{2}}$ & $\mid \begin{array}{l}0 \\
0 \\
0 \\
\end{array}$ & $\stackrel{0}{\Xi}$ & $\sum_{20}^{00}$ & $\begin{array}{l}0 \\
\tilde{J}\end{array}$ & $\begin{array}{l}0 \\
\tilde{Z}^{\prime} \\
\tilde{Z}^{\prime}\end{array}$ & $\begin{array}{l}0 \\
v^{\prime}\end{array}$ & $\omega$ & $\ddot{n}$ & $\mid F$ & $\varangle$ & $\mid \begin{array}{c}\pi \\
0 \\
0 \\
\\
\end{array}$ & {$[1$} & $\Xi$ & $\sum^{\infty}$ & $\tilde{U}$ & $\tilde{z}$ & 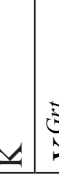 & 5 & $\begin{array}{l}5 \\
5 \\
\forall \\
\end{array}$ & 密 & 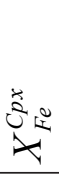 & 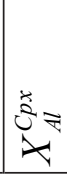 \\
\hline
\end{tabular}




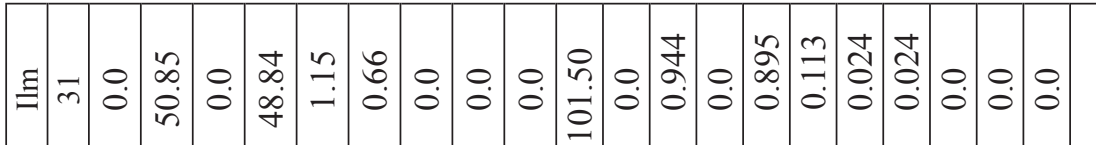

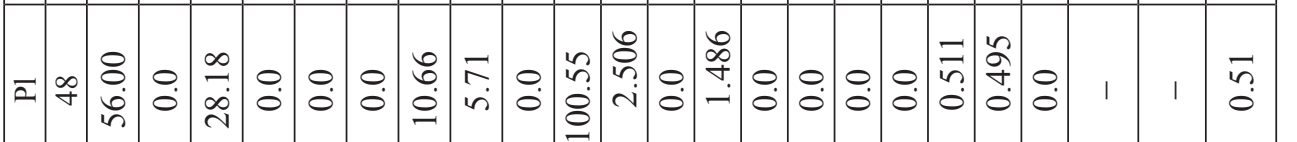

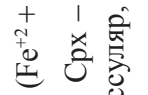
"I

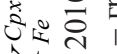
$\rtimes$ 造

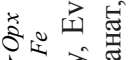
$\forall$ 或

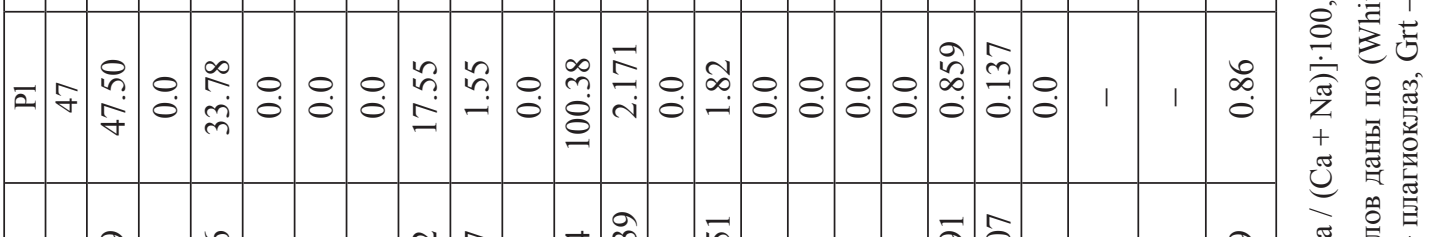

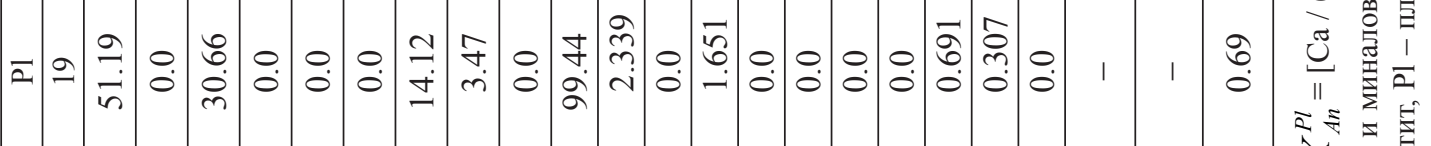

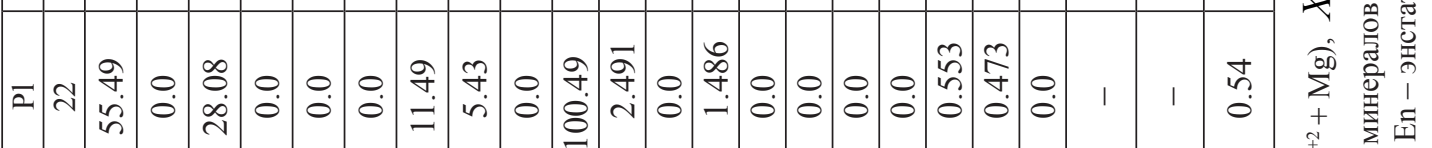

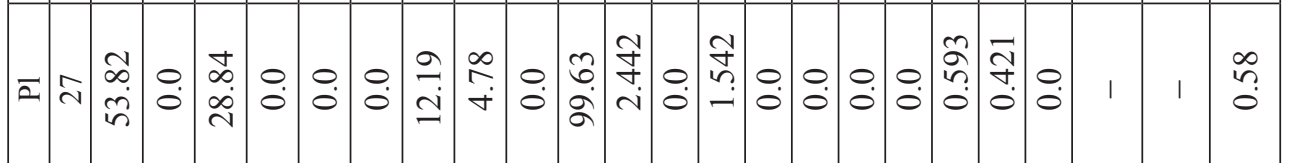

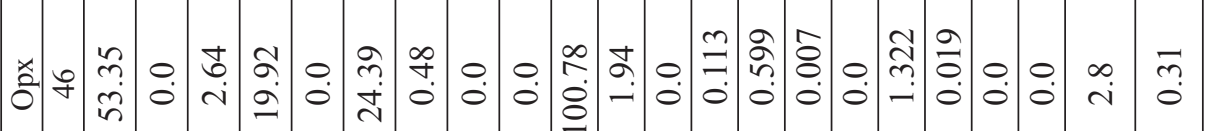

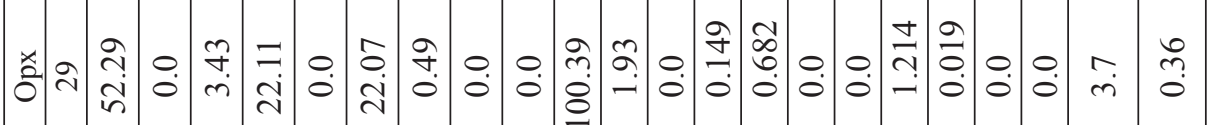
O仓்

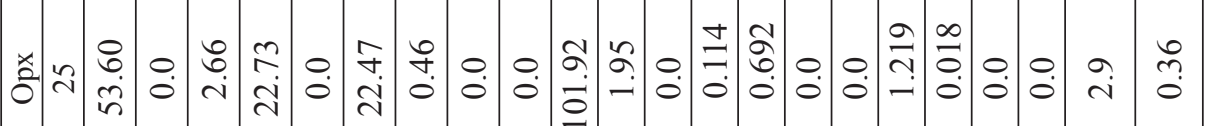
Oे

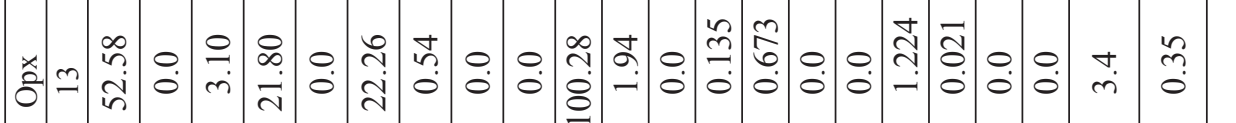

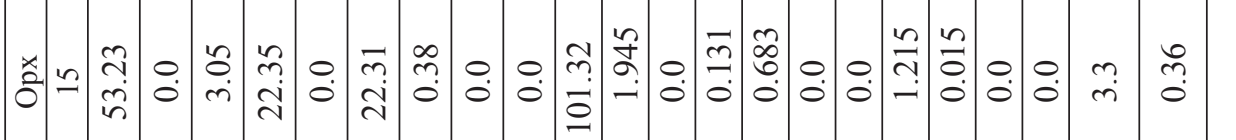

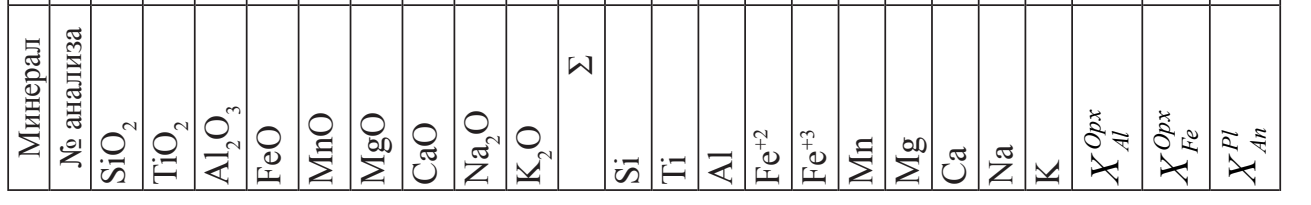

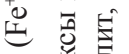
궁 용 11 羌

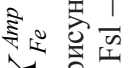
$\dashv$ 西 官䍃跑

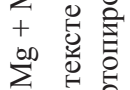
$+\infty$ 谣㐫 + हो के $+\frac{1}{0.0}$ ฮึ 和 嵹

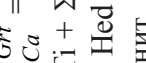
$\rtimes+$

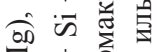
$\sum+2$ 世约

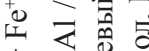
+4 质

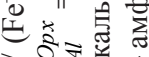
于 舟 。 作

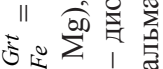
$\rightarrow+$.

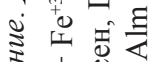
新星 部过亭亭 총 辞言 
Ортопироксен в этом шлифе вне реакционных структур не наблюдается. В симплектитах минералы представлены выделениями сложной червеобразной и петельчатой формы, иллюстрирующей, видимо, их одновременный рост (см. рис. 2). Химические анализы минералов, выполненные в точках, указанных на рис. 2 и 3, приведены в таблице.

Как видно из таблицы, края граната немного более железистые ( $X_{\mathrm{Fe}}^{\mathrm{Grt}}=0.56$, точка 12$)$ и более кальциевые ( $X_{C a}^{G r t}=0.29$, точка 35$)$, чем центры, $\left(X_{F e}^{G r t}=0.54 ; X_{C a}^{G r t}=0.22\right.$, точка 1$)$, а глиноземистость $\left(X_{A l}^{C p x}\right)$ клинопироксена может изменяться от 8.78 до 6.02 (см. таблицу, рис. 2, 3, точки 3, 36). Очень важно (см. далее), что более высокая глиноземистость клинопироксена устанавливается только в его включениях, находящихся целиком в кристаллах граната (точки 2, 3, см. рис. 3). Состав ортопироксена по глиноземистости и железистости изменяется незначительно (см. таблицу). Плагиоклаз, однако, обнаруживает очень резкую обратную зональность: содержание анортита $\left(X_{A n}^{P l}\right)$ меняется от 0.51 в центре до 0.86 в краевой части (см. таблицу). Это можно объяснить тем, что более кислые центральные зоны плагиоклаза отражают начальные условия метаморфизма, а более основные краевые - второй этап одновременный с образованием амфибола, поглощавшего натрий из плагиоклаза и распадом кальцийсодержащего граната. Амфибол в породе, так же как и ортопироксен, обнаруживает очень небольшую изменчивость состава (см. таблицу). По составу относится к магнезиальным паргаситам группы кальциевых амфиболов (Leake et al., 1997). Характеризуется высокой восстановленностью, так как не содержит трехвалентного железа, если рассчитывать его по минимальному условию (Schumacher, 1997). Другие минералы в породе, согласно расчету (см. таблицу), также содержат небольшие количества трехвалентного железа, что свидетельствует об их высокой восстановленности.

\section{ОПРЕДЕЛЕНИЕ Р-Т ПАРАМЕТРОВ В обр. 327}

Оценка условий образования рассматриваемого образца гранатовых метаультрамафитов проводится на основе внутренне согласованной программы TWQ (Berman, 2007), которая находится в свободном доступе (WinTWQ..., 2019). $\mathrm{C}$ ее помощью рассчитываются реакции в поле P-Т между миналами, составляющими минералы - гранат, клино- и ортопироксен, биотит, кордиерит, плагиоклаз, оливин, мусковит, шпинель, ильменит, амфибол, калиевый полевой шпат. Пересечение линий рассчитанных реакций на $\mathrm{P}-\mathrm{T}$ диаграмме для какого-либо минерального парагенезиса дает возможность оценить температуру и давление, при которых он формировался.
Однако оценка этих параметров для парагенезисов, в которых проявлены реакционные структуры, представляет особую сложность, поскольку в этом случае соотношения составов разных минералов могут быть далеки от химического равновесия, что может приводить к ошибочной оценке значений Р и Т. В связи с этим для выделения равновесных составов минералов необходимо пользоваться петрографическими критериями, хотя и они далеко не всегда бывают однозначными. Учитывая это замечание, перейдем к оценке Р-Т условий образования гранатовых метаультрамафитов обр. 327, причем вначале обратимся к минеральной ассоциации гранат + клинопироксен. Расчет по анализам 1 и 2 дает $\mathrm{P}=6700$ бар при температуре $940^{\circ} \mathrm{C}$, а по анализам 1 и 3 (рис. 4) $\mathrm{P}=7200$ бар при температуре $950^{\circ} \mathrm{C}$. Таким образом, средняя величина составит примерно 6950 бар при температуре $945^{\circ} \mathrm{C}$. Однако если расчет провести по анализам 35 и 36 (или 1 и 36), мы получим невероятную оценку давления в 18500 бар! Заметим, что клинопироксены (анализы 2, 3, см. таблицу) отличаются от клинопироксенов (анализы 36, 39) повышенным содержанием глинозема.

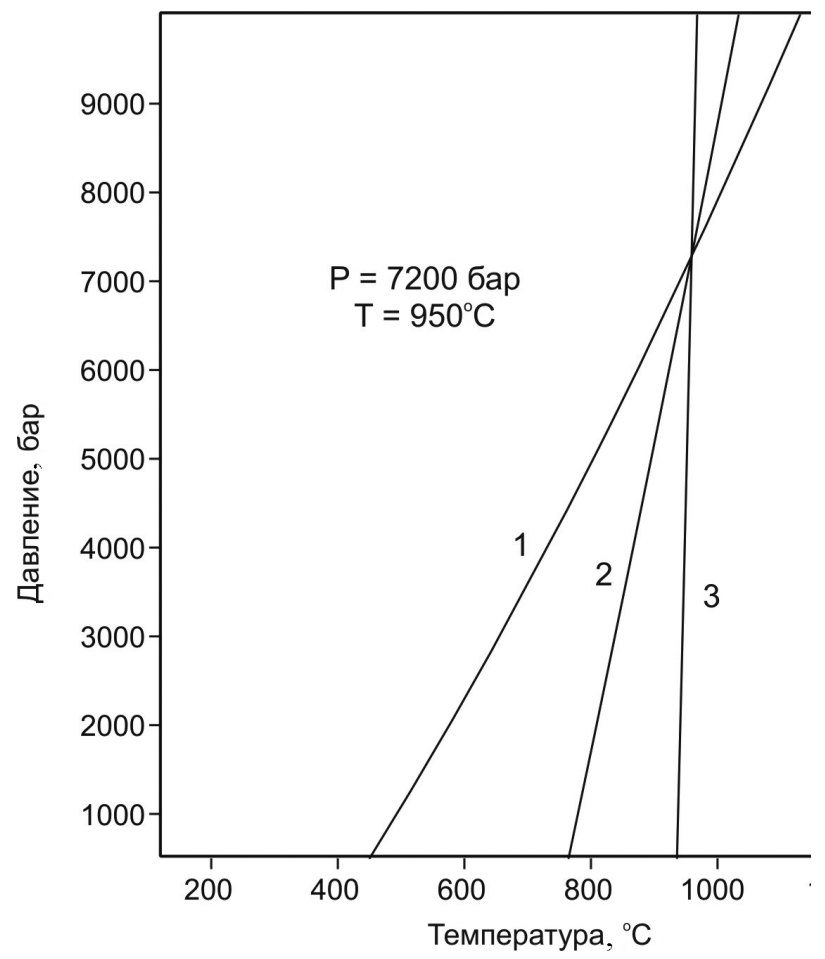

Puc. 4. Оценка Р-Т условий образования минерального парагенезиса Grt + Cpx в обр. 327, согласно анализам 1-3 (см. таблицу). Цифры на линиях - равновесия: $1-2 \mathrm{Grs}+\operatorname{Prp}=3 \mathrm{Di}+3 \mathrm{CTs} ; 2-\mathrm{Alm}+2 \mathrm{Grs}=$ $3 \mathrm{Hed}+3 \mathrm{Cts} ; 3-\mathrm{Alm}+3 \mathrm{Di}=\mathrm{Prp}+3 \mathrm{Hed}$

Fig. 4. Evaluation of the P-T conditions for the formation of the mineral paragenesis Grt + Cpx in Sample 327, according to analyses 1-3 (Table). The numbers on the lines mark equilibria: $1-2 \mathrm{Grs}+\operatorname{Prp}=3 \mathrm{Di}+3 \mathrm{CTs} ; 2-$ $\mathrm{Alm}+2 \mathrm{Grs}=3 \mathrm{Hed}+3 \mathrm{Cts} ; 3-\mathrm{Alm}+3 \mathrm{Di}=\mathrm{Prp}+3 \mathrm{Hed}$ 
Напомним (см. рис. 3), что клинопироксен (анализы 2 и 3) находится целиком внутри кристаллов граната, причем его контакты с гранатом четкие, без реакционных осложнений, тогда как клинопироксены (анализы 36 и 39) находятся за пределами гранатовых зерен, но примыкают к реакционной оторочке (см. рис. 2). Именно эти клинопироксены обладают пониженной глиноземистостью, что и приводит к значительно более высоким оценкам давления. Очевидно, что клинопироксены, включенные в гранат, значительно ближе к химическому равновесию с составом граната, чем те, которые примыкают к реакционной оторочке и находятся вне гранатовых зерен. Следовательно, оценку Р-Т параметров, равную 6950 бар при температуре $945^{\circ} \mathrm{C}$, надо принять как отвечающую условиям образования данного образца метаультрамафитов. Заключение о неравновесности составов 35 и 36 или 1 и 39 (см. таблицу) поддерживается расчетом Р-Т параметров по минеральной ассоциации гранат + ортопироксен. Оказывается, что расчет Р-Т параметров в паре Grt + Opx приводит также к невероятно высоким оценкам давления: $\mathrm{P}=22000$ бар (!) при температуре $1150^{\circ} \mathrm{C}$. Между тем вполне очевидно (см. рис. 2), что ортопироксен в обр. 327 появляется только в реакционных зонах и состав его может быть неравновесен с составом граната. Дело в том, что оценка давления по TWQ в парагенезисе Grt + Cpx + Opx определяется главным образом содержанием глинозема в минералах, причем уменьшение глиноземистости в пироксенах коррелируется с возрастанием давления. В то же время известна малая подвижность глинозема. Поэтому завышенная оценка давления может получаться из-за недопоглощения глинозема образующимися в процессе реакции пироксенами. Относительно небольшие вариации содержания глинозема в клино- и ортопироксенах, которые наблюдаются в реакционных структурах, могут приводить к неправильным выводам о режиме Р и Т. Вместе с тем не представляет сложности оценка температуры в равновесии Cpx + Opx по программе TWQ. Минальная реакции Fsl + Di $=\mathrm{En}+\mathrm{Hed}$ в равновесии Cpx + Opx очень слабо зависит от давления. Расчет по TWQ дает температуру этого равновесия по анализам 25 и 37 (см. таблицу, рис. 2) примерно $850^{\circ} \mathrm{C}$. Эту температуру можно принять как температуру образования реакционной каймы.

\section{СОПОСТАВЛЕНИЕ С РЕЗУЛЬТАТАМИ ПРЕДЫДУЩИХ ИССЛЕДОВАНИЙ}

На основе изучения реакционных структур, развитых в гранатовых жедрититах и сапфириншпинелевых метаультрамафитах (Авченко и др., 2018), мы получили Р-Т тренд регрессивной эво- люции метаморфизма Ауланджинского блока, с помощью которого объяснили генезис реакционных структур в обр. 329а и 329-5. Тренд был выведен по точкам А, В и С (рис. 5). Основанием для вывода Р-Т координат точек А-С послужило следующее: Р-Т координаты точки С (4.8 кбар и $840^{\circ} \mathrm{C}$ ) получены расчетом по TWQ на обр. 329a, точки В $\left(6\right.$ кбар и $\left.900^{\circ} \mathrm{C}\right)$ выведены на основе моделирования на программном комплексе «Селектор» сапфирин-шпинелевого равновесия в обр. $329-5$, а точки $\mathrm{A}\left(1000^{\circ} \mathrm{C}\right.$ и 7 кбар) определены путем экстраполяции линии В - С в поле шпинелевых гранулитов с учетом термометрических данных по циркону (Акинин, Жуланова, 2016) и результатов моделирования.

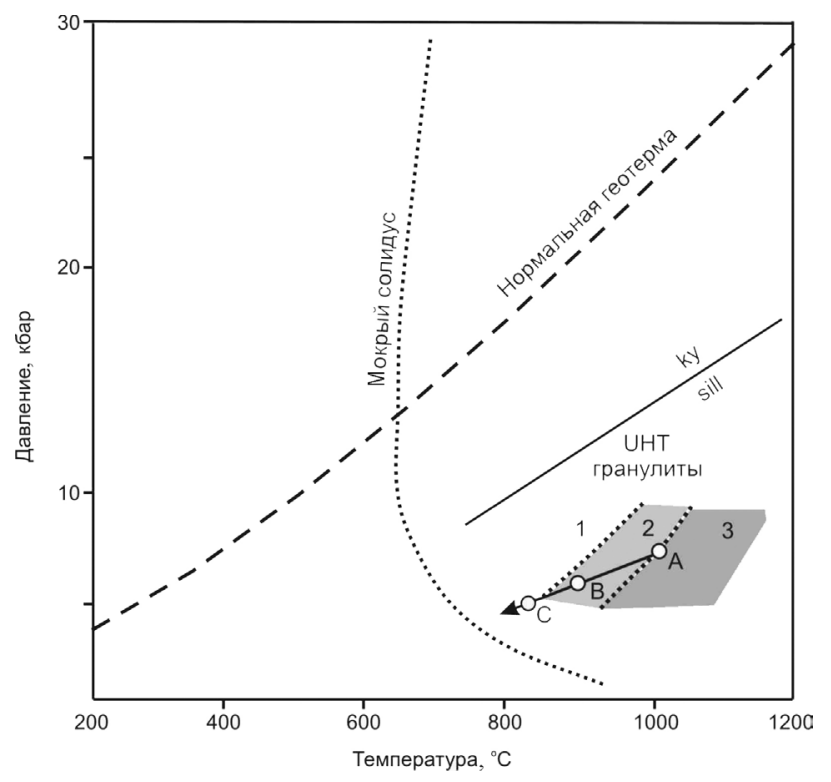

Puc. 5. Вероятный Р-Т тренд эволюции метаморфизма Ауланджинского блока по (Авченко и др., 2018). Точки В и С определены расчетом по гранатортопироксеновому геобаротермометру, встроенному в программу TWQ (точка C), и на основе моделирования обр. 329-5 (точка В). Точка А - экстраполяция линии В - С в поле шпинелевых гранулитов UHT - поле ультравысокотемпературных гранулитов (Kelsey, Hand, 2015). 1-3 - поля минеральных парагенезисов, рассчитанные по ПК «Селектор» на основе обр. 329-5: 1 - с сапфирином без шпинели, 2 - с сапфирином и шпинелью, 3 - со шпинелью без сапфирина

Fig. 5. Probable RT trend of the evolution of Aulandzha block metamorphism (Avchenko et al., 2018). Points $\mathrm{B}$ and $\mathrm{C}$ are determined by calculating the garnet-orthopyroxene geobarothermometer, embedded in the TWQ software ( Point C), and based on the simulation of Sample 329-5 (Point B). Point A is an extrapolation of the B $\mathrm{C}$ line in the field of spinel granulites UHT, the field of ultrahigh-temperature granulites (Kelsey \& Hand, 2015). 1-3 - fields of mineral parageneses calculated by the $\mathrm{Se}$ lector PC basing on Sample 329-5: 1 - with sapphyrine, no spinel, 2 - with sapphyrine and spinel, 3 - with spinel, no sapphyrine 
Положение точки А, отражающей максимальные Р-Т условия первоначального метаморфизма, оставалось наиболее сомнительным, поскольку прямых данных о величине давления на этом этапе у нас не было. Изучение обр. 327 привело, как показано ранее, к Р-Т параметрам, практически совпадающим с Р-Т координатами точки А. Скорее всего, Р-Т оценки максимальных условий метаморфизма пород Ауланджинского блока действительно были близки к 7000 бар при температуре $950-1000^{\circ} \mathrm{C}$. Температура образования реакционной каймы в обр. $327\left(850^{\circ} \mathrm{C}\right)$ очень близка к ранее определенной температуре реакционной каймы в обр. 329а (координаты точки С). Следовательно, возникновение реакционных кайм в гранатовых метаультрамафитах объясняется регрессивной эволюцией метаморфизма Ауланджинского блока по тренду Р-Т (см. рис. 5).

\section{ЗАКЛЮЧЕНИЕ}

1. Изучение реакционных структур в гранатовых метаультрамафитах Ауланджинского блока (обр. 327) показало, что составы пироксенов в этих структурах неравновесны с составом граната по содержанию глинозема, т. е. принцип локального равновесия в реакционных структуpax может нарушаться по малоподвижным компонентам. Пониженное содержание глинозема в пироксенах из реакционных структур (недопоглощение) является причиной нереально высоких оценок давления по программе TWQ в парагенезисах Grt + Opx или Grt + Cpx. В то же время составы зерен клинопироксенов, целиком включенных в гранат, дают оценки Р-Т, хорошо согласующиеся с результатами наших предыдущих исследований.

2. Сопоставление новых и ранее полученных данных (Авченко и др., 2018) позволяет более обоснованно заключить, что Р-Т параметры пика метаморфизма Ауланджинского блока были близки к значению давления 7000 бар при температуре $950-1000^{\circ} \mathrm{C}$.

3. Распознавание истинно равновесных составов первичных минералов - сложная задача, требующая петрографических наблюдений и статистически представительного микрозондирования. Относительно небольшие вариации содержания глинозема в клино- и ортопироксенах, наблюдаемые в реакционных структурах, могут приводить к неправильным выводам о режиме Р и Т.

\section{ЛИТЕРАТУРА}

Авченко О. В., Чудненко К. В., Вах А. С. Анализ минеральных парагенезисов методом минимизации потенциала Гиббса. М. : ГЕОС, 2018. 254 с.

Авченко О. В., Жуланова И. Л., Чудненко К. В., Карабиов $A$. A. Шпинель-сапфириновые реакционные структуры в гранатовых метаультрамафитах Омолонского массива: петрогенезис и геологическая интерпретация (Северо-Восток Азии) // Тихоокеан. геология. 2018. Т. 37, № 3. С. 15-31.

Акинин В. В., Жуланова И. Л. Возраст и геохимия циркона из древнейших метаморфических пород Омолонского массива (Северо-Восток России) // Геохимия. 2016. № 8. С. 675-684.

Бибикова Е. В. Уран-свинцовая геохронология ранних этапов развития древних щитов. М. : Наука, 1989. $179 \mathrm{c}$.

Гельман М. Л., Терехов М. И. Новые данные о докембрийском кристаллическом комплексе Омолонского массива // Метаморфические комплексы Востока СССР. Владивосток : ДВНЦ АН СССР, 1973. C. 66-73.

Жуланова И. Л., Авченко О. В., Шарова О. И. Гранатовые метаультрамафиты и гранатовые жедрититы Омолонского микроконтинента: глубинный диафторез и его геолого-тектоническая интерпретация (Северо-Восток России) // Фундамент. исследования. 2014. № 8. Ч. 6. С. 1393-1399. http:// search.rae.ru

Жуланова И. Л. Земная кора Северо-Востока Азии в докембрии и фанерозое. М. : Наука, 1990. 304 с.

Berman R. G. WinTWQ (version 2.3) : A software package for performing internally-consistent thermobarometric calculations // Geological Survey of Canada, Open File 5462, 2007, 41 p., ed. 2.32. https:// DOI: org/10.4095/223228 (Open Access).

Kelsey D. E., Hand M. On ultrahigh temperature crustal metamorphism: Phasequlibria, trace element thermometry, bulk composition, heat sources, timescales and tectonic settings // Geoscience Frontiers. 2015. 6 (3). P. 311-356. DOI: 10.1016/j.gsf.2014.09.006

Leake B. E., Wolly A. R., Arps C. E. S., et al. Nomenclature of amphiboles: Report of the Subcommitte on Amphiboles of the International Mineralogical Association Commission on new minerals and mineral names // European Journal of Mineralogy. 1997.9 (3). P. 623-652. DOI: $10.1127 /$ ejm/9/3/0623

Schumacher J. C. The estimation of ferric iron in electron microprobe analysis of amphiboles // Mineralogical Magazine. 1997. Vol. 61. Is. 405. P. 312-321. https://DOI. org/10.1017/S0026461X00011397

Whitney D. L., Evans B. W. Abbreviations for names of rock-forming minerals // American Mineralogist. 2010. 95 (1). P. 185-187. https://DOI: org/10.2138/ am.2010.3371.

WinTWQ Program description [Электрон. pecypc]. http://twq.petrochronology.org (дата обр. 15.03.2019). 


\title{
EXPERIENCE OF PETROLOGICAL INTERPRETATION OF REACTIONARY STRUCTURES IN GARNET METAULTRAMAFITES OF THE OMOLON MASSIF
}

\author{
O. V. Avchenko', I. L. Zhulanova ${ }^{2}$, A. A. Karabtsov ${ }^{I}$ \\ ${ }^{1}$ Far East Geological Institute, FEB RAS, Vladivostok \\ ${ }^{2}$ North-East Interdisciplinary Scientific Research Institute n. a. N. A. Shilo, FEB RAS, Magadan \\ The reactionary structures in garnet metaultramafites from the Aulandzha block of the Omolon \\ massif, imprinted in kelyphite rims, built by orthopyroxene, plagioclase, hornblende, rarely by \\ clinopyroxene and surrounding garnet, are studied. Calculations of P-T parameters by coexisting \\ compositions of garnets and pyroxenes on the basis of the TWQ program testify to violation of the \\ local equilibrium principle in reactionary structures in the alumina potential. The lowered alumina \\ content in pyroxenes from reactionary structures causes unrealistically high pressure values. \\ Simultaneourly, if P-T values are calculated by the composition of clinopiroxene incusions located \\ inside garnet crystals and the coexisting garnet composition, the metamorphism P-T parameters are \\ well consistent with earlier results. New data permit to conclude that, when the deepest-seated rocks \\ were formed, pressure was about 7000 bars under the temperature of $950-1000^{\circ} \mathrm{C}$.
}

Keywords: Omolon massif, metamorphism, TWQ program, reactionary structures, alumina potential.

\section{REFERENCES}

Akinin, V. V.; Zhulanova, I. L., 2016, Isotopic Age and Geochemistry of Zircon from the Most Ancient Metamorphic Rocks of the Omolon Massif (North-East of Russia), Geochemistry International, 8, 675-684 [In Russian].

Avchenko, O. V.; Chudnenko, K. V.; Vakh, A. S., 2018, Analysis of Mineral Parageneses by the Method of Minimizing the Gibbs Potential, Moscow, GEOS [In Russian].

Avchenko, O. V.; Zhulanova, I. L.; Chudnenko, K. V.; Karabtsov, A. A., 2018, Spinel-Sapphyrine Reactionary Structures in Garnet Metaultramafites of the Omolon Massif: Petrology and Geological Interpretation (NorthEast of Asia), Russian Journal of Pacific Geology, 37, 3, 15-31 [In Russian].

Berman, R. G., 2007, WinTWQ (Version 2.3): A Software Package for Performing Internally-Consistent Thermobarometric Calculations, Geological Survey of Canada, Open File 5462, 41, ed. 2.32, https://DOI. org/10.4095/223228 (Open Access).

Bibikova, E. V., 1989, Uranium-Lead Geochronology of Early Stages of Ancient Shields Development, Moscow, Nauka Publishers [In Russian].

Gelman, M. L.; Terekhov, M. I., 1973, New Data on a Pre-Cambrian Crystalline Complex of the Omolon Massif, Metamorphic Complexes of the East of the USSR, Vladivostok, DVNC AN USSR, 66-73 [In Russian].

Kelsey, D. E.; Hand, M., 2015, On Ultrahigh Temperature Crustal Metamorphism: Phasequlibria, Trace Element Thermometry, Bulk Composition, Heat Sources,
Timescales, and Tectonic Settings, Geoscience Frontiers, 6 (3), 311-356, DOI: 10.1016/j.gsf.2014.09.006

Leake, B. E.; Wolly, A. R.; Arps, C. E. S.; Birch, W. D.; Gilbert, M. C.; Grice, J. D.; Howthorne, F. C.; Kato, A.; Kisch, H. J.; Krivovichev, V. G.; Linthout, K.; Laird, J.; Mandarino, J.; Maresch, W. V.; Nickel, E. H.; Rock, N. M. S.; Schumacher, J. C.; Smith, D. C.; Stephenson, N. C. N.; Ungaretti, L.; Whitaker, E. J. W.; Youzhi G., 1997, Nomenclature of Amphiboles: Report of the Subcommitte on Amphiboles of the International Mineralogical Association Commission on New Minerals and Mineral Names, European Journal of Mineralogy, 9 (3), 623-652, DOI: 10.1127/ejm/9/3/0623

Schumacher, J. C., 1997, The Estimation of Ferric Iron in Electron Microprobe Analysis of Amphiboles, Mineralogical Magazine, 61, 405, 312-321, https://DOI. org/10.1017/S0026461X00011397

Whitney, D. L.; Evans, B. W., 2010, Abbreviations for Names of Rock-Forming Minerals, American Mineralogist, 95 (1), 185-187, https://DOI: org/10.2138/ am.2010.3371

WinTWQ Program Description [Electron. a Resource], http://twq.petrochronology.org (ref. date 15.03.2019).

Zhulanova, I. L., 1990, Earth Crust in the North-East of Asia in the Pre-Cambrian and Phanerozoic, Moscow, Nauka Publishers [In Russian].

Zhulanova, I. L.; Avchenko, O. V.; Sharova, O. I., 2014, Garnet Metaultramafites and Garnet Gedritites of the Omolon Microcontinent: Deep Diaphthoresis and Its Geological and Tectonic Interpretation (North-East of Russia), Fundamental Research, 8, 6, 1393-1399, http://search.rae.ru [In Russian]. 